\section{Sunk without a trace}

\section{June Goodfield}

The Mind Has No Sex? Women in the Origins of Modern Science. By Londa Schiebinger. Harvard University Press: 1989. Pp.355. \$29.50, £23.50.

"LET us now praise famous men, and our fathers that begat us", runs the verse from Ecclesiasticus. Not, you notice, that women or mothers were in any way involved nor were they likely to have been present in the writer's mind even as he concluded: "And some there be which have no memorial. Who are buried as though they had never been". It was ever thus, I concluded, as I finished Londa Schiebinger's remarkable book.

Its title comes from an assertion made over 300 years ago by Francois Pollain de la Barre, as part of an attempt to secure a place for women in the then emerging modern science. The author of this book adds a question mark to his phrase - not because she has any doubts about the matter but, I believe, because over the centuries thousands have stated equally assertively that the fairer sex is also the weaker, both mentally as well as physically. And they have appealed to a whole range of rationales - themselves socially and culturally determined, subject equally to the whims of fashion or assumption to underpin their preferred judgements. By now no one, I trust, denies that during history women have been largely excluded from scientific institutions (as indeed they have from almost all other institutions) and the mechanisms of exclusion, whether structural, sexual or derived from supposed gender differences, are still largely in operation. Schiebinger's intention is not to add to the burgeoning literature on this topic but to try to understand what these gender differences are, and how they operate in science today. Her chosen method is to examine the past - the revolution in European science in the seventeenth and eighteenth centuries to be precise - in order to answer this problem: what role did the "women question" and the debate over "female nature" play in the origins of modern science?

This is a formidable task, but it has been undertaken by someone of formidable scholarship who is blessed with one additional gift: she understands that social and historical dynamics are highly complex yet has remained undaunted. Halfdan Mahler, when Director General of the World Health Organization, commented recently that "development is a very messy affair" and added "God protect me from the simplifiers". The point applies to this issue too. If we are to make any progress at all in understanding the present inequities, let alone rectify them, we need to eschew simplicity and generalizations and do full justice to the underlying human complexity.

Accordingly, the author approaches her analysis from four different angles but always with the question of gender to the forefront - that is, are men and women different by nature or by nurture; if so, what difference does (and did) this difference make? She explores in turn, first, the institutions of science which in the period under discussion were fostered in a variety

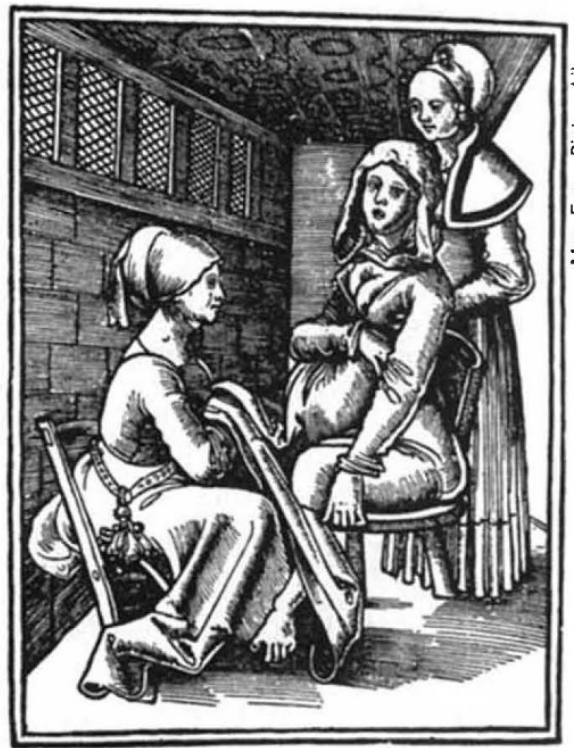

Labour pains - midwives became auxiliaries in a male-dominated medical system.

of settings (academies, Parisian salons, princely courts and craftsmen's workshops); second, the lives of some women, predominantly from the aristocracy and the crafts, who pressed against the boundaries of convention to practise science; third, how the biological sciences traditionally merged sex (a matter of genes) with gender (a matter of culture, education and expectations) to produce supposedly scientific readings about the female nature that were used equally by those who argued for, or against, women's full participation in science. Finally, her gaze is directed towards the cultural meanings of femininity and masculinity, and how a woman's ability to do science has seemingly become irreparably meshed into issues of gender.

No one of these elements is, she rightly insists, a causal agent that alone determines where women are in science today. Each, however, had a part in the process, and in the dynamic that determined the present outcome they have all played important and interdependent roles.

The extent of research and the material uncovered is remarkable. Where and how did Schiebinger find it all? For this is intellectual archaeology at its very best, and a landscape is laid out for us the existence of which most readers will be totally igno- rant. There are some surprises along the way: matters were not totally ever thus.

Although the extent of women's activity, success and penetration into science varied from class to class and country to country, their ultimate exclusion was not a foregone conclusion. Aristocratic women dominated the discussions in the salons of seventeenth-century Paris; women artesans did notable astronomical and agricultural research in Germany; the Enlightenment was a great time to be alive, when women's desire to be involved in science was assisted by many social trends and even the bastions of some of the new scientific academies were temporarily breached. Yet time after time all such efforts were stymied and it is ironic that the ultimate coup de grâce was to come from the very enterprise that women tried to develop. For modern science, too, finally came to codify a view of women that set the seal on their exclusion.

But there is, of course, more than one way to skin a cat, as the history of midwives illustrates. Since ancient times this 'craft' group had peacefully co-existed alongside medical men, each with their own art and monopoly. But both the peace and monopoly were to be shattered in the two centuries in question. Whereas doctors, surgeons, apothecaries, dentists and veterinarians gradually transformed themselves into self-governing, selfregulating professions, midwives never succeeded in doing this though they certainly tried. But still they remained regulated by men - by the King's chief barber-surgeon in Paris, by the clerics in England. Finally, the accoucheur appeared - the man-midwife who was now called in for routine cases, not just abnormal labours. By the end of the eighteenth century, midwives were just auxiliaries to a male-dominated medical system: the practice of obstetrics and gynaecology passed over to men.

This example is telling for it illustrates the nature of one of the Catch-22 traps that ensnared so many women who wished to progress in science. Midwives could not learn new methods or practices because they could neither attend universities nor establish their own medical colleges; they could not do those things simply because they were women. No matter what arguments they employed, what authorities they quoted - from the Bible to the new ethnology - to try to secure their ancient privileges, it was hopeless. And when finally they were driven to the argument of 'natural propriety' matters were made even worse. For 'natural innateness' was the final appeal that, above all, kept the women at the hearth in their traditional child-bearing roles.

In giving this account of the role of science in the creation of gender, backed by this mass of fascinating detail, intriguingly interpreted, Schiebinger has truly 
travelled uncharted territory. But has she really answered her own question? Societies "intent on preserving the sharp social and intellectual distinctions between the sexes" have, for the most part, deliberately cultivated perceived sexual differences. But what are these? Do they indeed exist; if so, what difference does the difference make?

Here these questions are posed rather than answered. Unravelling the multifarious strands of women's role in the history of modern science is an essential first step, brilliantly executed in this book. It is to be hoped that this study will pro- voke further analysis into the contemporary scene and present powerful trends in science. For every Maxine Singer, now President of the Carnegie Institution of Washington, there are still hundreds of others striving to make their mark in the scientific enterprise in conditions where Catch-22 traps still operate. Will it be ever thus? Sometimes I'm optimistic, but reading what happened in history, and not yet discerning overpowering new trends, sometimes I wonder whether such optimism is justified.

June Goodfield is at The Manor House, Alfriston, Polegate, Sussex BN26 5SY, UK.

\section{Asking questions}

\section{Igor Aleksander}

Ideas and Information: Managing in a High-tech World. By Arno Penzias. W.W. Norton: 1989. Pp. 224. \$17.95, £12.95.

For many people, phrases such as 'the information age' or 'high-tech world' evoke feelings of the hackneyed, the oversold. Not so for Arno Penzias, who sees 'managing in a high-tech world' as a matter of exciting discovery and wonderment. In Ideas and Information, Penzias, a Nobel laureate for physics in 1979, glances over his own specialist fence at the nature of information technology and the effects it has had on him and the world he inhabits. The world 'managing' in the subtitle is used in the sense of 'coping': Penzias is a technology enthusiast. His book is intended to give heart to those who feel that coping in a world of faxes, electronic mail, word processing, databases and the like is getting beyond them.

The style is anecdotal without being trivial, authoritative without being overpowering. And it has to be enthusiastic because, after all, Penzias is the vicepresident for research of one of the world's most renowned information-technology companies: AT\&T's Bell Telephone Laboratories. The anecdotes add fun and a personal touch to what could so easily otherwise have been yet another dull catalogue of the benefits bestowed on mankind by the advent of computers. Penzias also goes to great lengths to distinguish the rule-enslaved computer from the free-learning, exploration-loving human being. I suppose that there are still those who get the two confused to the extent that such descriptions are necessary.

The book is written with an implied sense of history: the history of symbols, the history of mathematics and the history of computing machines. Penzias argues that the manipulation of symbols distinguishes computers from other machines in the way that being able to use symbols distinguishes human beings from animals.
Symbols were valued by the prehistoric painters of the images in the Lascaux caves in France, by the Sumerians of 3300 $\mathrm{BC}$ who invented information storage (tokens in a clay jar), and by the Egyptians and the Chinese, who raised application of their intelligence to higher planes by inventing numbers and mathematics. So, for Penzias, the computer is the ultimate celebration of human intelligence: a machine that embodies the finest points of the use of symbols and manipulations.

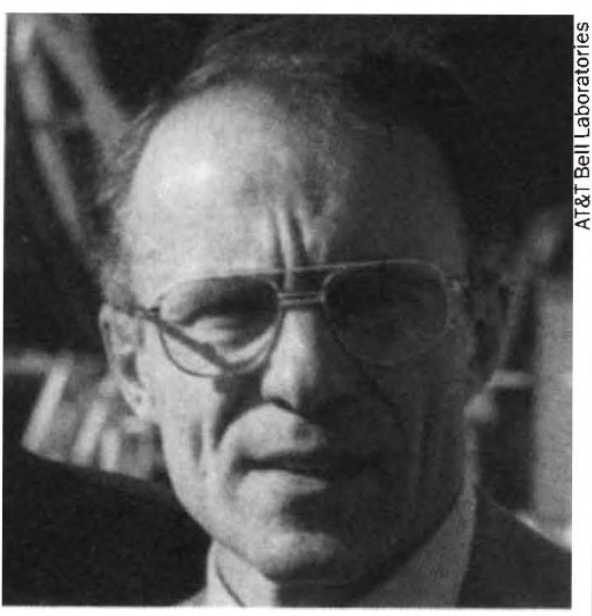

Arno Penzias - "cheerful optimism".

He does not confuse person and machine, however, as seen in this almost thrown-away footnote: "As we explore the computer's ability to match human information-processing capabilities, we shouldn't overlook the fact that these machines have much to offer society without emulating humans". At the same time as he creates the distinction between living and mechanical information processors, he pinpoints the very factor which, if mechanized, could reduce this crucial distance: "On the other hand, I am sure that this situation will change drastically when (and if) we can devise a computing architecture that learns from examples, the way humans do, rather than merely obeying instructions. Nature produces countless billions of such computers in the brains of living creatures". In these sentences he has identified (perhaps unwittingly) the scent that the contem- porary hounds of neural-network research have sniffed out, and that is leading them towards learning computers with which they will try to revolutionize computing by narrowing the gap between the mechanical and the biological.

The mix of anecdote, history and insightful comment is a characteristic of the book as a whole. Penzias describes milestones in the making of information machines such as Chomsky's analysis of language, Hopfield's revival of neural nets and Joseph Weizenbaum's totally mechanical 'psychiatrist emulator', Eliza, which makes its interlocutors think that it 'understands' their problems, while it is simply throwing their own words, modified by a few simple rules, back at them.

For me, a high point is reached in Penzias's recounting of I.I. Rabi's description of the reasons for his (Rabi's) success, also crowned by the Nobel prize in physics. "Have you asked any good questions today?", his mother would ask him on his return from school. This, surely, rather than just the ability to learn, must be the factor that best distinguishes organisms that possess intelligence from those that do not. The ones that do ask very good questions.

There are some unfortunate blemishes. Bell Labs is presented as the source of all discovery, which will irritate readers who happen to know that not all high-tech inventions were made at that institution. For example, the comment "At Bell Labs . . a robotics research group has built a robot that can follow spoken instructions" is followed by a description of work that was done by Terry Winograd at the Massachusetts Institute of Technology in the early 1970 s. There is no mention of Winograd. Even Hopfield is described as a Bell Labs' physicist, giving no credit to the fact that he is also an academic at Caltech.

But perhaps the worst sin is that there is no mention of the down side of computers: the overrating of technology for its own sake; the fact that the purchase of information technology in a badly managed organization can amplify the bad management; the need to change one's behaviour to meet the needs of computerdriven procedures (as in banks); new opportunities for fraud; the possibility that people may be forced to become less skilled as well as more skilled. For Penzias these difficulties do not exist, or if they do he may have decided to ignore them for fear of damaging the up-beat tempo of his book. Without a doubt those who need reassurance about coping in the information age will be rewarded by the cheerful optimism purveyed in Ideas and Information. Why spoil it with bad news?

Igor Aleksander is in the Department of Electrical Engineering, Imperial College, London SW7 5BT, UK 